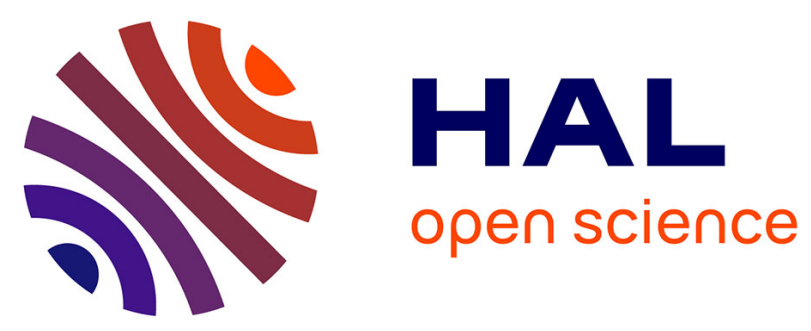

\title{
The effect of linker of electrodes prepared from sol?gel ionic liquid precursor and carbon nanoparticles on dioxygen electroreduction bioelectrocatalysis
}

Katarzyna Szot, Robert P. Lynch, Adam Lesniewskia, Ewa Majewska, Juliette Sirieix-Plénet, Laurent Gaillon, Marcin Opallo

\section{To cite this version:}

Katarzyna Szot, Robert P. Lynch, Adam Lesniewskia, Ewa Majewska, Juliette Sirieix-Plénet, et al.. The effect of linker of electrodes prepared from sol?gel ionic liquid precursor and carbon nanoparticles on dioxygen electroreduction bioelectrocatalysis. Electrochimica Acta, 2011, 56 (28), pp.10306-10312. 10.1016/j.electacta.2011.03.139 . hal-01519098

\section{HAL Id: hal-01519098 \\ https://hal.sorbonne-universite.fr/hal-01519098}

Submitted on 15 Jun 2017

HAL is a multi-disciplinary open access archive for the deposit and dissemination of scientific research documents, whether they are published or not. The documents may come from teaching and research institutions in France or abroad, or from public or private research centers.
L'archive ouverte pluridisciplinaire HAL, est destinée au dépôt et à la diffusion de documents scientifiques de niveau recherche, publiés ou non, émanant des établissements d'enseignement et de recherche français ou étrangers, des laboratoires publics ou privés. 


\title{
The effect of linker of electrodes prepared from sol-gel ionic liquid precursor and carbon nanoparticles on dioxygen electroreduction bioelectrocatalysis
}

\author{
Katarzyna Szot ${ }^{a}$, Robert P. Lyncha ${ }^{b}$, Adam Lesniewski ${ }^{a}$, Ewa Majewska ${ }^{a}$, Juliette Sirieix-Plenet ${ }^{c, d, e}$, Laurent \\ Gaillon ${ }^{\mathrm{c}, \mathrm{d}, \mathrm{e}}$, Marcin Opalloa ${ }^{\mathrm{f}, *}$
}

\author{
a Institute of Physical Chemistry, Polish Academy of Sciences, ul. Kasprzaka 44/52, 01-224 Warszawa, Poland \\ ${ }^{\mathrm{b}}$ Department of Physics/Materials and Surface Science Institute, University of Limerick, Ireland \\ c UPMC Univ. Paris 06, UMR 7195, Laboratoire de Physicochimie des Electrolytes, Colloïdes et Sciences \\ Analytiques (PECSA), F-75005 Paris, France \\ d CNRS, UMR 7195 PECSA, F-75005 Paris, France \\ e ESPCI, UMR 7195, PECSA, F-75005 Paris, France \\ ${ }^{f}$ Faculty of Mathematics and Natural Sciences, College of Sciences, University of Cardinal Stefan Wyszynski, \\ Warszawa, Poland
}

* Corresponding author at: Institute of Physical Chemistry, Polish Academy of Sciences, ul. Kasprzaka 44/52, 01224 Warszawa, Poland. Tel.: +48 22343 3375; fax: +48 223433333.

E-mail address: mopallo@ichf.edu.pl (M. Opallo).

\section{Keywords:}

Ionic liquid, Sol-gel, Layer-by-layer, Carbon nanoparticles, Bioelectrocatalysis

\begin{abstract}
A bstract
The effect of linker of three-dimensional, hydrophilic-carbon-nanoparticle film-electrodes prepared by layer-bylayer method on redox probe accumulation and bioelectrocatalytic dioxygen reduction was studied and compared for two different electrode scaffolds. The linker in both of these scaffolds was based on the same ionic liquid sol-gel precursor, 1-methyl-3-(3-trimethoxysilylpropyl) imidazolium bis(trifluoromethyl-sulfonyl)imide. The first electrode type was prepared by alternative immersion of tin doped indium oxide substrate in an aqueous suspension of carbon nanoparticles modified with phenyl sulphonic groups and a sol composed of ionic liquid sol-gel precursor and tetramethoxysilane. For the second electrode type sol was replaced by a methanolic suspension of silicate submicroparticles with appended imidazolium functional groups. In both films 2,2-azinobis(3-ethylbenzothiazoline-6- sulfonate) anions accumulate irreversibly. In the case of the first electrode electrostatic attraction plays the more important role in comparison to the case of the second where stable adsorption of the redox probe takes place. After adsorption of bilirubin oxidase, electrodes obtained from sol and carbon nanoparticles exhibit modest bioelectrocatalytic activity towards dioxygen reduction at $\mathrm{pH} 4.8$, however those obtained from oppositely charged particles are much more efficient. The magnitude of the associated catalytic current in both cases depends on the number of immersion and withdrawal steps. Interestingly, mediatorless catalysis at electrodes obtained from oppositely charged particles is more efficient than mediated catalysis.
\end{abstract}

\section{Introduction}

In the last few years the design and application of ionic liquid (IL) modified electrodes has become an intensively explored research area [1-5]. Most of these electrodes consist of a mixture of IL and other components such as conductive and/or nonconductive (nano) particles, polymers and biomolecules and have a form of bulk substrate or film. The electrodes modified with appended ILs represent another class. Typically, imidazolium cation based substituent is (i) covalently bonded to polymer film [6-15], (ii) self-assembled on the electrode surface [16], (iii) covalently bonded to the electrode surface [17] or (iv) used forfunctionalization of conductive elements of the film [18]. The electrodes modified with imidazolium functionalized polymers are prepared by (i) chemical grafting of imidazolium functionalities and solution casting [6-10], (ii) surface initiated polymerization [14], (iii) polymerization of vinyl appended imidazolium cation and solution casting [15] or (iv) sol-gel processing of sol containing imidazolium appended trialkoxysilane [11-13]. The counterions are electrostatically attracted to 
positively charged functionalities and are exchanged after immersion into electrolyte solution. These polymer film electrodes exhibit high ionic conductivity and stability in aqueous solution. Due to the presence of cationic functional groups they exhibit accumulation of anions with some degree of specificity [9-12] and in particular they restrict access of cationic redox probes $[12,14]$. Furthermore, they exhibit catalytic behavior towards NADH oxidation [6] and provide suitable environments for enzyme encapsulation [10].

The polymers with charged functional groups are applied as a linker for construction of three dimensional nanoparticulate films at the electrode surface using a so-called layer-by-layer (LbL) approach [19]. Due to electrostatic attraction between these functionalities and oppositely charged conductive nanoobjects, stable three-dimensional conductive nanoparticulate networks can be prepared (see for example Refs. [20-23]). Such a platform is often selected as a substrate for enzymes, because conductive nanoobjects provide favourable conditions for direct electron transfer to/from the electrode. An alternative and almost neglected approach involves replacement of polymer with functionalized polymer particles as the linker [24,25]. Recently we have demonstrated that with sol-gel technology employing ionic liquid precursor 1-methyl-3-(3 trimethoxysilylpropyl)imidazolium bis(trifluoromethylsulfonyl)imide (Scheme 1) it is possible to prepare such a film using LbL procedures [11,25]. That is, carbon nanoparticles (CNPs) functionalised with phenyl sulphonic groups can be either linked by imidazolium functionalised silicate (Scheme 2, electrode (1)) [11] or by imidazolium functionalized silicate submicroparticles (Scheme 2, electrode (2)) [25].

Clearly the comparison of the different electrodes provides unique opportunity to study the effect of linker on the electrode processes. Using this opportunity we study and compare accumulation of redox mediator and bioeletrocatalysis of dioxygen in this paper. It is an important aspect of layer-by-layer film preparation that it allows for increase and control of the bioelectrocatalytic activity (see for example Refs. [26-29]). As redox mediator we selected 2,2_-azino-bis(3-ethylbenzothiazoline-6- sulfonate) (ABTS ${ }^{2-}$ ) and as biocatalyst we employed bilirubin oxidase (BOx) - a member the family of copper oxidoreductases.

The studies of BOx modified electrodes are powered by their potential application as cathodes in biofuel cells [30-34]. This enzyme significantly decreases the overpotential of dioxygen evolution at far from extreme $\mathrm{pH}$ values [35-37] and is superior in terms of activity under simulated physiological conditions at neutral $\mathrm{pH}$ and in the presence of $\mathrm{Cl}$ - anions [30,37-39]. The behaviour of Box modified electrode was studied in the presence $[35,40-44]$ and absence $[36,45-54]$ of accumulated ABTS ${ }^{2-}$ mediator and we show that the linker type used in constructing the electrode architecture is crucial for the efficiency of both mediated and mediatorless bioelectrocatalytic processes.

\section{Experimental}

\subsection{Chemicals and materials}

Tetramethoxysilane (TMOS) (99\%) and 2,2_-azino-bis(3-ethylbenzothiazoline-6-sulfonate) diammonium salt $\left(\left(\mathrm{NH}_{4}\right)_{2} \mathrm{ABTS}\right)$ were purchased from Aldrich. Methanol was from Chempur.

Ethanol, formic acid, $\mathrm{Na}_{2} \mathrm{HPO}_{4}, \mathrm{NaH}_{2} \mathrm{PO}_{4}$ and $\mathrm{HCl}$, all analytical grade, were from $\mathrm{POCH}$. $\mathrm{NaClO}_{4}$ was from Fluka. Carbon nanoparticles with phenylsulfonic acid surface functionalities (ca $7.8 \mathrm{~nm}$ mean diameter, Emperor 2000) were obtained from Cabot Corporation (Dukinfield, United Kingdom). Sn-doped In2O3 (ITO) coated glass (resistivity 15-30 $\Omega$ per square) was obtained from Image Optics Components Ltd., Basildon, Essex, UK. Water was filtered and demineralised with an ELIX system (Millipore). All reagents were used as received.

Synthesis of ionic liquid precursor 1-methyl-3-(3-trimethoxysilylpropyl) imidazolium bis(trifluoromethylsulfonyl)imide (Scheme 1) has being described previously [8]. Imidazolium appended silicate submicroparticles were prepared according to the modified procedure described in one of our previous papers [55]. BOx from Myrothecium sp. (EC 1.3.3.5) with activity of $2.82 \mu \mathrm{mg}^{-1}$ was kindly donated by Amano Enzyme Inc.

\subsection{Electrode modification}

The ITO plates were cleaned with ethanol, then with deionized water and finally heated for 30 min in a tube furnace (Barnstead International) at $500{ }^{\circ} \mathrm{C}$ in air. The electrode surface was defined by masking the electrode with scotch tape so as to expose a surface of area $0.2 \mathrm{~cm}^{2}$. The electric contact was assured by a piece of copper tape held by a 'crocodile clip' to the conducting side of the ITO glass. Two types of electrodes (Scheme 2) were prepared. Electrode (1) was fabricated by alternative immersion of ITO substrate firstly in an aqueous suspension of CNPs and secondly in an imidazolium appended precursor and TMOS methanol based sol containing formic acid catalyst [11]. Electrode (2) was obtained by alternative immersion of ITO substrate firstly in methanol suspension of imidazolium appended silicate submicroparticles solution and secondly in an aqueous suspension of CNPs [25]. For both electrodes the appropriate procedure was repeated until the desired number of layers 
was deposited on the electrode surface. Mechanically stable electrodes were obtained for up to a maximum of 10 such steps $(n=10)$ in the case of $(1)$, whereas for electrode $(2)$ stable films with a maximum $n=36$ steps were obtained. Enzyme adsorption was performed by immersion of nanoparticulate film electrodes in $1 \mathrm{mg} \mathrm{cm}^{-3} \mathrm{BOx}$ solution in $\mathrm{pH} 4.8$ phosphate buffer for $2 \mathrm{~h}$ at ca $5{ }^{\circ} \mathrm{C}$.

\subsection{Instrumentation and cell}

Cyclic voltammetry was performed with a $\mu$ Autolab (Eco Chemie) electrochemical system in a conventional three-electrode cell with dedicated software. The modified ITO electrodes along with platinum wire and $\mathrm{Ag}|\mathrm{AgCl}| \mathrm{KCl}_{\text {sat. }}$. electrodes were used as the working, counter and reference electrode, respectively. All experiments were carried out in quiescent conditions at $22 \pm 2 \circ \mathrm{C}$.

\section{Results and discussion}

3.1. 2,2-Azino-bis(3-ethylbenzothiazoline-6-sulfonate accumulation)

Accumulation of $A B T S^{2-}$ was achieved by immersion of electrode (1) or (2) in $1 \mathrm{mmol} \mathrm{dm}^{-3}\left(\mathrm{NH}_{4}\right) 2 \mathrm{ABTS}$ aqueous electrolyte solution [11] and was detected by cyclic voltammetry. After a gradual increase of the voltammetric peak current due to the reaction

$\mathrm{ABTS}^{2-}(\mathrm{acc}) \leftrightarrow \mathrm{ABTS}^{\bullet-}(\mathrm{acc})+\mathrm{e}^{-}$

to its maximal value the electrode was removed, washed with water and immersed in phosphate buffer ( $\mathrm{pH} 4.8)$. Both types of electrode exhibit stable voltammetry connected with electrochemical redox reaction (1) (Fig. 1) indicating irreversible mediator accumulation. The peak current density is proportional to the number of immersion and withdrawal cycles (Fig. 2). Clearly, when a larger amount of material is deposited at the electrode surface, a greater amount of mediator ions is accumulated. Also the increase of capacitive current related to the electroactive surface is observed for both electrodes (Fig. 1). However, some differences between their behaviour can be seen. For electrode (1) the redox potential of accumulated mediator shifts positively by $0.15 \mathrm{~V}$ as compared to that obtained at bare ITO in the presence of mediator in solution, whereas for electrode (2) no difference can be seen. This can be explained by a difference in the mechanism of accumulation. The lack of redox potential shift for electrode (2) shows $\mathrm{ABTS}^{2-}$ adsorption on CNPs, due to attractive interactions between delocalised $\Pi$ electrons in the extended aromatic system. This is confirmed by the linear dependence of peak current density on scan rate. Indeed, adsorption of this mediator on other carbon based materials such as microporous carbon [56,57], carbon nanotubes [58,59] and graphene [60] has been recently reported. This mechanism of accumulation seems to be less important for electrode (1). Here stabilisation of the reduced form of the mediator indicates attraction between its sulfonic functional groups and imidazolium functional groups of silicate. Moreover the peak current dependence on scan rate can be approximated by a polynomial with exponent between 0.5 and 1.0 indicating some attached $\mathrm{ABTS}^{2-}$ mobility. How electrode type affects the difference between peak potentials $(\Delta E)$ is also seen. For electrode (1) the effect is greater for larger $n$, reaching a maximum of $0.1 \mathrm{~V}$ for $\mathrm{n}=10$. In an earlier study [13] we showed that the resistance of this electrode was estimated in the range of 200-500 $\Omega$ perhaps resulting from the separation of CNPs by a polymer network. Such a resistance would result in a contribution towards the observed $\Delta \mathrm{E}$ of $0.01 \mathrm{~V}$ for the peak current densities observed at a scan rate of $0.01 \mathrm{~V} \mathrm{~s}^{-1}$. It follows that it is more likely that $\Delta \mathrm{E}$ is on account of some mobility of the encapsulated mediator - which is held in place by the positive charge of the functional groups of the silicate polymer - as exemplified by the observed peak currents scan-rate dependence. On the other hand_E is equal to only a few millivolts for electrode (2) which along with the linear scan rate dependence of the peak currents shows that mediator is adsorbed on CNPs. This indicates that heterogenous electron transfer is relatively fast as observed earlier for dissolved mediator [35].

\subsection{Mediated bioelectrocatalysis}

The voltammetric behaviour seen after accumulation of BOx for both electrodes when immersed in dioxygen saturated solution (Fig. 3) indicates bioelectrocatalysis of dioxygen reduction. Similarly as proposed by Tsujimura et al. [35] accumulated mediator is oxidized by BOx:

$\mathrm{BOx}(4 \mathrm{Cu}(\mathrm{II}))+\mathrm{ABTS}^{2-}(\mathrm{acc}) \leftrightarrow \mathrm{ABTS}^{\circ-}(\mathrm{acc})+\mathrm{BOx}(4 \mathrm{Cu}(\mathrm{I}))(2)$ 
$\mathrm{BOx}(4 \mathrm{Cu}(\mathrm{I}))+\mathrm{O}_{2}+4 \mathrm{H}+\rightarrow 2 \mathrm{H}_{2} \mathrm{O}+\mathrm{BOx}(4 \mathrm{Cu}(\mathrm{II}))(3)$

and these steps are followed by electrochemical regeneration of the mediator:

$\mathrm{ABTS}^{\bullet-}(\mathrm{acc})+\mathrm{e}-\leftrightarrow \mathrm{ABTS}^{2-}(\mathrm{acc})(4)$

The electrode architecture does not affect the onset potential of catalytic current, however electrode (2) is superior in terms of catalytic current density. For electrode (2) this parameter is proportional to $n$, whereas in the case of electrode (1) maximum current density is obtained for electrode prepared by five immersion and withdrawal steps. Although it is difficult to estimate the amount of accumulated and active BOx molecules, because of the lack of direct electrochemical signal, one can speculate that the smaller voids of electrode (1) restrict accumulation of the enzyme in the film electrode. The other reason of more efficient catalysis at electrode (2) is the more negative value observed for the redox potential of the mediator (see Fig. 1).

The active site of BOx consists of a T2/T3 cluster of copper ions coordinated to 4 histidines that is responsible for dioxygen binding and a T1 copper ion surrounded by histidine, cysteine and methionine that is important for electron transfer $[61,62]$. The most recent estimate of T1 redox potential indicates a value of $0.45 \mathrm{~V}$

[63]. This clearly shows that at electrode (1) the $\mathrm{ABTS}^{2-/{ }^{--}}$redox potential is shifted in an unfavourable direction. The sigmoidal shape of voltammograms obtained at $0.001 \mathrm{~V} \mathrm{~s}^{-1}$ (with some peak developments for large amounts of nanoparticulate material) may indicate that the reaction kinetics are controlled by supply of dioxygen to the active site of the enzyme. However at faster scan rates (up to $0.1 \mathrm{~V} \mathrm{~s}^{-1}$ ) a gradual transition from sigmoidal to peak shaped curves is seen (Fig. 4) indicating slow kinetics of the catalytic reaction. At slower scan rate a large fraction of the reduced form of the mediator is consumed in the catalytic reaction, whereas at faster scan rate it is reoxidized electrochemically. The behaviour we observe may result from the slowest reduction step, where four $\mathrm{Cu}$ ions at the active site of the enzyme are fully oxidized [64, 65]. This voltammetric pattern was earlier observed for electrodes with immobilised $\mathrm{ABTS}^{2-}$ and other copper oxidoreductase, e.g. laccase, catalysing dioxygen reduction within the same range of scan rates $[66,67]$. The detailed analysis of kinetic results is complicated not only by the lack of a reliable estimate for the amount of adsorbed enzyme but also by the electrode architecture.

Most importantly the form of the electrode material is not suitable for rotating disc electrode (RDE) experiments which would allow for a detailed analysis of the bioelectrocatalytic reaction (see for example Refs. [68,69]). Furthermore attempts to perform RDE experiments using similar film preparation on glassy carbon or Au electrodes do not produce films stable enough to perform these experiments. Therefore the above discussion can be only qualitative and some contribution from mediatorless bioelectrocatalysis on $\mathrm{ABTS}^{2-}$ modified electrodes cannot be ruled out.

\subsection{Mediatorless bioelectrocatalysis}

In the absence of accumulated mediator, adsorbed BOx also exhibits catalytic activity on both electrodes and the effect of electrode architecture is clearly seen. In this case the superiority of electrode (2) in terms of current density is even more striking (Fig. 5). Instead of a modest bioelectrocatalytic effect, a catalytic current density of greater than $0.3 \mathrm{~mA} \mathrm{~cm}$-2 is seen for slow scan rate voltammetric experiments for the largest amount of the immobilized material on electrode (2). Similar or larger mediatorless catalytic activity was already seen for other carbon based materials in quiet solution or using RDE [36,45-52]. Also in the case of electrode (2) this parameter is proportional to the value of $n$, whereas for electrode (1) the maximal activity is seen for three immersion and withdrawal steps. The chronoamperometric experiments show that during first hour catalytic current quickly drops to ca. $50 \%$ of its initial value. However after two days the electrode retains ca. $40 \%$ of its initial activity (Fig. 6). This can be caused either by desorption of the enzyme from the film and/or decrease of its activity. Further experiments with electrode (2) reveal that in air saturated solution the catalytic current density is ca. four times smaller than in dioxygen saturated solution (Fig. 7). Interestingly, some catalytic signal is observed in deaerated solution, perhaps due to dioxygen encapsulated in the nanoparticulate material as it has been suggested for carbon ceramic electrode modified with Box [46]. More importantly, these results indicate that mediatorless catalytic activity of the electrode is controlled by dioxygen supply [50]. This effect seen when one compares the mediated and mediatorless catalytic activity of both electrodes is quite interesting. The catalytic current of electrode (1) in the absence of mediator is about half of that observed with accumulated ABTS ${ }^{2-}$. This can be interpreted as the opening of a new reaction path due to immobilization of mediator resulting in increased electrocatalytic activity [52,59]. However for electrode (2) an opposite effect is observed: electrodes with accumulated $\mathrm{ABTS}^{2-}$ show reduced activity with respect to their mediatorless equivalents. This clearly indicates 
that CNPs on their own provide more favourable conditions for electron exchange with adsorbed BOx than they do with adsorbed $\mathrm{ABTS}^{2-}$. The important role of aromatic functional groups as anthracene or anthraquinone in mediatorless bioelectrocatalysis by copper oxidoreductases has been recently advocated (see Refs. $[45,46,70,71])$. It was proposed that these functionalities act as a plug into the hydrophobic pocket of copper oxidoreductase - facilitating electron transfer between the active T1 site and electrode substrate. Recently such aromatic compounds with negatively charged functional groups including sulfonates adsorbed on multiwalled [72] or single walled carbon nanotubes (SWCNTs) $[50,73]$ were shown to significantly increase efficiency of the same reaction. The study of $B O D$ dioxygen reduction electrocatalysis on single crystal gold shows that the presence of sulfonate functionalities at the electrode surface enhances reaction efficiency [74]. This together with similar performance of phenylsulfonated CNPs immobilised in various ways $[25,51,75,76]$ indicates the importance of the attachment of the sulfonate group to the aromatic substituent for efficient dioxygen bioelectrocatalysis. One can estimate the electrode capacitance and amount of adsorbed mediator from cyclic voltammograms (Fig. 2). Interestingly, crude calculations, based on the assumptions of real CNPs surface capacity equal to $10^{-5} \mathrm{~F} \mathrm{~cm}^{-2}$ and single $A B \mathrm{~S}^{2-}$ ion coverage of the surface equal to $1.7 \mathrm{~nm}^{2}$ [77], show that assuming flat orientation of the mediator almost all the electroactive surface is covered. Therefore one may conclude that the bioelectrocatalytic activity of film electrode consisting of CNPs is more effective than that of composed of CNPs and $\mathrm{ABTS}^{2-}$ ions. Although we were not able to find in literature the comparison of bioelectrocatalytic activity of BOx modified electrodes in the presence and absence of immobilised mediator on the same electrode material, there are two examples of such data for laccase (another copper oxidoreductase capable of catalysing dioxygen reduction) on modified electrodes $[59,78]$. For the electrode modified with multiwalled carbon nanotubes, silicate film adsorption of $\mathrm{ABTS}^{2-}$ increases by ten times its bioelectrocatalytic activity towards dioxygen reduction [59]. On the other hand the covalent modification of single walled carbon nanotubes (SWCNTs) with $\mathrm{ABTS}^{2-}$ moiety does not affect or even decrease bioelectric activity of SWCNTs-Nafion-laccase film [78]. From these and our results one may conclude that the effect of immobilised mediator as compared to mediatorless bioelectrocatalysis depends on the electrode material, mediator immobilisation and perhaps the type of the enzyme. The limited number of data does not allow for more general conclusion to be drawn.

\section{Conclusions}

The above manuscript shows not only successful application of sol-gel ionic-liquid precursor to the preparation of bioelectrocatalytic electrodes modified with bilirubin oxidase, but more importantly presents a comparison of the effect of linker on the electrochemical properties of two types of layer-by-layer formed electrodes. These electrodes are prepared using different linker types (i.e., either polymer or submicroparticles) - both of which are based on the same precursor - and hydrophilic phenylsufonate functionalised carbon nanoparticles as the second component.

Although comparable amounts of ABTS2- can be irreversibly accumulated in these film electrodes their modes of immobilisation are different. For electrode (2) - prepared from oppositely charged particles - adsorption of this mediator takes place, whereas for electrode (1) - with sol-gel silicate as a linker - electrostatic interactions between silicate and CNPs functionalities play an important role. After adsorption of BOx both electrodes exhibit both mediated and mediatorless dioxygen bioelectrocatalysis. However the electrode consisting of imidazolium appended submicroparticles (2) is superior in terms of catalytic efficiency. The magnitude of

mediatorless bioelectrocatalytic current density obtained in slow voltammetric conditions in quiescent solution is similar to that obtained with: BOx adsorbed on carbon powder encapsulated in Nafion film [45], functionalised SWCNTs encapsulated in silicate film [50], carbon ceramic electrode enriched with CNPs [51], three dimensional gold nanoparticulate electrodes [53] and platinum nanoparticle composite [79]. It seems to be also similar to that obtained on carbon aerogel film [37], functionalised pyrolytic graphite [49,52] and carbonaceous micro/macrocellular foams [54], however this comparison is not straightforward, since the data of these papers were obtained at rotating disc electrodes.

Our results show that the almost neglected procedure of layer-by-layer electrode preparation based on oppositely charged particles should be tested for other bioelectrocatalytic and other reactions. The use of the sol-gel processed silicate for enzyme modified electrodes is especially attractive, because of the stabilizing properties of this material $[80,81]$. Certainly for the system studied the use of oppositely charged particles instead of sol-gel processing at the surface provides significant improvement of the catalytic efficiency. Furthermore, it must be emphasized that these significant improvements in catalytic efficiency are achieved through an electrode preparation procedure that is fast and simple. However prospective application of this material as biocathode requires more stable immobilisation of the enzyme. 


\section{Acknowledgements}

Helpful discussion with Dr. Martin Jonsson-Niedziolka is gratefullyacknowledged.

This work was partially sponsored by the Ministry of Science and Education (project NN204 3687 33). We thank Cabot Corporation for generous support with carbon nanoparticle materials and Amano Enzyme Inc. for donation of bilirubin oxidase from Myrothecium sp. (EC 1.3.3.5). One of the authors, R.P. Lynch, would like to acknowledge the receipt of an IRCSET-Marie Curie International Mobility Fellowship in Science, Engineering and Technology (grant no. INSPIRE PCOFUND-GA-2008-229520).

\section{References}

[1] P. Hapiot, C. Lagrost, Chem. Rev. 108 (2008) 2238.

[2] D. Wei, A. Ivaska, Anal. Chim. Acta 607 (2008) 126.

[3] M. Opallo, A. Lesniewski, J. Niedziolka, E. Rozniecka, G. Shul, Rev. Polarogr. 54 (2008) 21.

[4] Y.R. Wang, P. Hu, Q.L. Liang, G.A. Luo, Y.M. Wang, Chin. J. Anal. Chem. 36 (2008) 1011.

[5] M. Opallo, A. Lesniewski, J. Electroanal. Chem. (2011), doi:10.1016/ j.jelechem.2011.01.008.

[6] Y Shen, Y. Zhang, Q. Zhang, L. Niu, T. You, A. Ivaska, Chem. Commun. (2005) 4193.

[7] D. Han, X. Qiu, Y. Shen, H. Guo, Y. Zhang, L. Niu, J. Electroanal. Chem. 596 (2006) 33.

[8] F. Li, C. Shan, X. Bu, Y. Shen, G. Yang, L. Niu, J. Electroanal. Chem. 616 (2008) 1.

[9] Y. Shen, Y. Zhang, X. Qiu, H. Guo, L. Niu, A. Ivaska, Green Chem. 9 (2007) 746.

[10] F. Yang, L. Jiao, Y. Shen, X. Xu, Y. Zhang, L. Niu, J. Electroanal. Chem. 608 (2007) 78.

[11] K. Szot, A. Lesniewski, J. Niedziolka, M. Jonsson, C. Rizzi, L. Gaillon, F. Marken, J. Rogalski, M. Opallo, J. Electroanal. Chem. 623 (2008) 170.

[12] A. Lesniewski, J. Niedziolka, B. Palys, C. Rizzi, L. Gaillon, M. Opallo, Electrochem. Commun. 9 (2007) 2580.

[13] A. Lesniewski, M. Jonsson-Niedziolka, J. Niedziolka-Jonsson, C. Rizzi, L. Gaillon, M. Opallo, Electroanalysis 21 (2009) 701.

[14] B. Yu, F. Zhou, H. Hu, C. Wang, W. Liu, Electrochim. Acta 53 (2007) 487.

[15] Q. Zhang, X. Lu, Y. Qiao, L. Zhang, D.L. Liu, W. Zhang, G.X. Han, X.M. Song, Electroanalysis 22 (2010) 1000.

[16] Y.S. Chi, S. Hwang, B.S. Lee, J. Kwak, I.S. Choi, S.-g. Lee, Langmuir 21 (2005) 4268.

[17] M. Wang, A. Schneider, J. Niedziolka-Jonsson, L. Marcon, S. Ghodbane, D. Steinmuller-Nethl, M. Li, R. Boukherroub, S. Szunerits, Electrochim. Acta 55 (2010) 1582.

[18] Z.J. Wang, Q.X. Zhang, D. Kuehner, X.Y. Xu, A. Ivaska, L. Niu, Carbon 46 (2008) 1687.

[19] G. Decher, J.D. Hong, Ber. Bunsen-Ges. Phys. Chem. 95 (1991) 1430.

[20] J.F. Hicks, Y.S. Shon, R.W. Murray, Langmuir 18 (2002) 2288.

[21] H. Zhang, N. Lu, N. Hu, J. Phys. Chem. B 110 (2006) 2171.

[22] M. Amiri, S. Shahrokhian, F. Marken, Electroanalysis 19 (2007) 1032.

[23] L. Rassaei, M.J. Bonne, M. Sillanpaa, F. Marken, New J. Chem. (2008) 1253.

[24] L. Zhang, F. Wang, S.J. Dong, Electrochim. Acta 53 (2008) 6423.

[25] A. Lesniewski, J. Niedziolka-Jonsson, C. Rizzi, L. Gaillon, J. Rogalski, M. Opallo, Electrochem. Commun. 12 (2010) 83.

[26] C.A. Paddon, F. Marken, Electrochem. Commun. 6 (2004) 1249.

[27] N. Chang, H. Lu, N. Hu, J. Phys. Chem. B 110 (2006) 17478.

[28] L. Deng, L. Shang, Y.Z. Wang, T. Wang, H.J. Chen, S.J. Dong, Electrochem. Commun. 10 (2008) 1012.

[29] R. Szamocki, V. Flexer, L. Levin, F. Forchiasin, E.J. Calvo, Electrochim. Acta 54 (2009) 1970.

[30] A. Heller, Phys. Chem. Chem. Phys. 6 (2004) 209.

[31] S.C. Barton, J. Gallaway, J.P. Atanassov, Chem. Rev. 104 (2004) 4867.

[32] S.D. Minteer, B.Y. Liaw, M.J. Cooney, Curr. Opin. Biotechnol. 18 (2007) 228.

[33] I. Willner, M.Y. Yan, B. Willner, R. Tel-Vered, Fuel Cells 9 (2009) 7.

[34] J.A. Cracknell, K.A. Vincent, F.A. Armstrong, Chem. Rev. 108 (2008) 2439.

[35] S. Tsujimura, B. Tatsumi, J. Ogawa, S. Shimizu, K. Kano, T. Ikeda, J. Electroanal. Chem. 496 (2001) 69.

[36] S. Tsujimura, Y. Kamitaka, K. Kano, Fuel Cells 7 (2007) 463.

[37] N. Mano, H.H. Kim, Y.C. Zhang, A. Heller, J. Am. Chem. Soc. 124 (2002) 6480.

[38] S. Tsujimura, K. Kano, T. Ikeda, Electrochemistry 70 (2002) 940.

[39] C. Kang, H. Shin, A. Heller, Bioelectrochemistry 68 (2006) 22. 
[40] A. Habrioux, G. Merle, K. Servat, K.B. Kokoh, C. Innocent, M. Cretin, S. Tingry, J. Electroanal. Chem. 622 (2008) 97.

[41] J. Lim, N. Cirigliano, J. Wang, B. Dunn, Phys. Chem. Chem. Phys. 9 (2007) 1809.

[42] J. Lim, P. Malati, F. Bonet, B. Dunn, J. Electrochem. Soc. 154 (2007) A140.

[43] S. Komaba, T. Mitsuhashi, S. Shraishi, Electrochemistry 76 (2008) 619.

[44] G. Merle, A. Habrioux, K. Servat, M. Rolland, C. Innocent, K.B. Kokoh, S. Tingry, Electrochim. Acta 54 (2009) 2998.

[45] C.F. Blanford, R.S. Heath, F.A. Armstrong, Chem. Commun. (2007) 1710.

[46] L. dos Santos, V. Climent, C.F. Blanford, F.A. Armstrong, Phys. Chem. Chem. Phys. 12 (2010) 13962.

[47] V. Flexer, N. Brun, O. Courjean, R. Backov, N. Mano, Energy Environ. Sci. (2011), doi:10.1039/C0EE00466A.

[48] K. Murata, K. Kajiya, N. Nakamura, H. Ohno, Energy Environ. Sci. 2 (2009) 1280.

[49] S. Tsujimura, T. Nakagawa, K. Kano, T. Ikeda, Electrochemistry 72 (2004) 437.

[50] M. Jonsson-Niedziolka, A. Kaminska, M. Opallo, Electrochim. Acta 55 (2010) 8744.

[51] W. Nogala, A. Celebanska, K. Szot, G. Wittstock, M. Opallo, Electrochim. Acta 55 (2010) 5719.

[52] A. Habrioux, T. Napporn, K. Servat, S. Tingry, K.B. Kokoh, Electrochim. Acta 55

(2010) 7701.

[53] S. Shleev, J. Tkac, A. Christenson, T. Ruzgas, A.I. Yaropolov, J.W. Whittaker, L. Gorton, Biosens. Bioelectron. 20 (2005) 2517.

[54] S. Shleev, A. El Kasmi, T. Ruzgas, L. Gorton, Electrochem. Commun. 6 (2004) 934.

[55] A. Lesniewski, J. Niedziolka-Jonsson, J. Sirieix-Plenet, L. Gaillon, M. Opallo, Electrochem. Commun. 11 (2009) 1305.

[56] K. Servat, S. Tingry, L. Brunel, S. Querelle, M. Cretin, C. Innocent, C. Jolivalt, M. Rolland, J. Appl. Electrochem. 37 (2007) 121.

[57] L. Brunel, J. Denele, K. Servat, K.B. Kokoh, C. Jolivalt, C. Innocent, M. Cretin, M. Rolland, S. Tingry, Electrochem. Commun. 9 (2007) 331.

[58] K. Karnicka, K. Miecznikowski, B. Kowalewska, M. Skunik, M. Opallo, J. Rogalski, W. Schuhmann, P. Kulesza, Anal. Chem. 80 (2008) 7643.

[59] M. Jonsson, K. Szot, J. Niedziolka, K. Karnicka, P. Kulesza, J. Rogalski, M. Opallo, J. Nanosci. Nanotechnol. 9 (2009) 2346.

[60] X.M. Wu, Y.J. Hu, J. Jin, N.L. Zhou, P. Wu, H. Zhang, C.X. Cai, Anal. Chem. 82 (2010) 3588.

[61] E.I. Solomon, U.M. Sundaram, T.E. Machonkin, Chem. Rev. 96 (1996) 2563.

[62] K. Mizutani, M. Toyoda, K. Sagara, N. Takahashi, A. Sato, Y. Kamitaka, S. Tsujimura, Y. Nakanishi, T. Sugiura, S. Yamaguchi, K. Kano, B. Mikami, Acta Cryst. F66 (2010) 765.

[63] P. Ramirez, N. Mano, R. Andreu, T. Ruzgas, A. Heller, L. Gorton, S. Shleev, Biochim. Biophys. Acta 1777 (2008) 1364.

[64] S.K. Lee, S. DeBeer George, W.E. Antholine, B. Hedman, K.O. Hodgson, E.I. Solomon, J. Am. Chem. Soc. 124 (2002) 6180.

[65] D.L. Johnson, J.L. Thompson, S.M. Brinkmann, K.A. Schuller, L.L. Martin, Biochemistry 42 (2003) 10229.

[66] W. Nogala, E. Rozniecka, I. Zawisza, J. Rogalski, M. Opallo, Electrochem. Commun. 8 (2006) 1850.

[67] K. Szot, J. Niedziolka, J. Rogalski, F. Marken, M. Opallo, J. Electroanal. Chem. 612 (2008) 1.

[68] S.D. Varfolomeev, I.V. Berezin, J. Mol. Catal. 4 (1978) 387.

[69] V.J. Razumas, J.J. Jasaitis, J.J. Kulys, Bioelectrochem. Bioenergy 12 (1984) 297.

[70] M. Sosna, J.-M. Chretien, J.D. Kilburn, P.N. Bartlett, Phys. Chem. Chem. Phys. 12 (2010) 10018.

[71] M.S. Thorum, C.A. Anderson, J.J. Hatch, A.S. Campbell, N.M. Marshall, S.C. Zimmerman, Y. Lu, A.A. Gewirth, J. Phys. Chem. Lett. 1 (2010) 2251.

[72] G. Gobel, F. Lisdat, Electrochem. Commun. 10 (2008) 1691.

[73] M. Jonsson-Niedziolka, K. Szot, J. Rogalski, M. Opallo, Electrochem. Commun. 11 (2009) 1042.

[74] M. Tominaga, M. Ontani, I. Taniguchi, Phys. Chem. Chem. Phys. 10 (2008) 6928.

[75] K. Szot, J.D. Watkins, S.D. Bullen, F. Marken, M. Opallo, Electrochem. Commun. 12 (2010) 737.

[76] A. Lesniewski, M. Paszewski, M. Opallo, Electrochem. Commun. 12 (2010) 435.

[77] A. Denis, K. Boubekeur, P. Molinie, P. Leone, P. Palvadeau, J. Mol. Struct. 689 (2004) 25.

[78] K. Sadowska, K. Stolarczyk, J.F. Biernat, K.P. Roberts, J. Rogalski, R. Bilewicz, Bioelectrochemistry 80 (2010) 73.

[79] Y.-M. Yan, I. Baravik, R. Tel-Vered, I. Willner, Adv. Mater. 21 (2009) 4275.

[80] S. Braun, S. Rappoport, R. Zusman, D. Avnir, M. Ottolenghi, Mater. Lett. 10 (1990) 1.

[81] D. Avnir, S. Braun, O. Lev, M. Ottolenghi, Chem. Mater. 6 (1994) 1605 


\section{Captions :}

Scheme 1. The structural formula of sol-gel precursor 1-methyl-3-(3- trimethoxysilylpropyl)imidazolium bis(trifluoromethylsulfonyl)imide.

Scheme 2. Scheme of preparation of electrodes (1) and (2).

Fig. 1. Cyclic voltammograms obtained in $0.1 \mathrm{~mol} \mathrm{dm}^{-3}$ phosphate buffer ( $\mathrm{pH} \mathrm{4.8)}$ at (A) a bare ITO electrode (i) and electrodes (1) prepared by one (ii) three (iii), five (iv) or ten (v) immersion and withdrawal steps and (B) electrodes (2) prepared by one (i) six (ii), twelve (iii) and twenty-four (iv) immersion and withdrawal steps. Both electrodes (1) and (2) were further modified with $\mathrm{ABTS}^{2-}$. Geometric surface area, $0.2 \mathrm{~cm}^{2}$; and scan rate, $0.01 \mathrm{~V}$ $\mathrm{s}^{-1}$.

Fig. 2. The dependence of the (A) capacitive current and (B) anodic peak current density obtained under the same conditions as Fig. 1 on the number of immersion and withdrawal steps ( $n$ ) for electrode (1) (full) and electrode (2) (open).

Fig. 3. Cyclic voltammograms obtained in dioxygen saturated $0.1 \mathrm{~mol} \mathrm{dm}^{-3}$ phosphate buffer solution (pH 4.8) at electrodes further modified with $\mathrm{ABTS}^{2-}$ and BOx (A) of type (1) prepared by one (i) three (ii), five (iii) or ten (iv) immersion and withdrawal steps and (B) of type (2) prepared by one (i) six (ii), twelve (iii) and twenty-four (iv) immersion and withdrawal steps. Geometric surface area, $0.2 \mathrm{~cm}^{2}$; and scan rate, $0.001 \mathrm{~V} \mathrm{~s}^{-1}$.

Fig. 4. Cyclic voltammograms obtained in dioxygen saturated $0.1 \mathrm{~mol} \mathrm{dm}^{-3}$ phosphate buffer $(\mathrm{pH} 4.8)$ at an electrode (2) prepared by twenty-four immersion and withdrawal steps and further modified with ABTS ${ }^{2-}$ and BOx. Scan rates: $0.001,0.01,0.02,0.05$ and $0.1 \mathrm{~V} \mathrm{~s}^{-1}$. Arrow shows increasing scan rate.

Fig. 5. Cyclic voltammograms obtained in dioxygen saturated $0.1 \mathrm{~mol} \mathrm{dm}^{-3}$ phosphate aqueous buffer solution $(\mathrm{pH} 4.8)$ at electrodes further modified with BOx (A) of type (1) prepared by one (i) three (ii), five (iii) or ten (iv) immersion and withdrawal steps and (B) of type (2) prepared by one (i), two (ii), eight (iii), sixteen (iv), and thirtytwo (v) immersion and withdrawal steps. Geometric surface area, $0.2 \mathrm{~cm}^{2}$; and scan rate, $0.001 \mathrm{~V} \mathrm{~s}^{-1}$.

Fig. 6. Chronoamperograms obtained with the electrodes of type (2) prepared by (i) two, (ii) four, (iii) sixteen and (iv) thirty-two immersion and withdrawal steps and further modified with BOx. The curves were obtained in dioxygen saturated $0.1 \mathrm{~mol} \mathrm{dm}^{-3}$ Mcllvaine buffer $(\mathrm{pH} 4.8)$ at a potential of $0.2 \mathrm{~V}$ using electrodes with $0.2 \mathrm{~cm}^{2}$ geometric surface area.

Fig. 7. Cyclic voltammograms obtained in argon (i), air (ii) and dioxygen saturated (iii) $0.1 \mathrm{~mol} \mathrm{dm}^{-3} \mathrm{Mcllvaine}$ buffer ( $\mathrm{pH}$ 4.8) for an electrode (2) prepared by thirty two immersion and withdrawal steps and further modified with BOx. Geometric surface area, $0.2 \mathrm{~cm}^{2}$; scan rate, $0.001 \mathrm{~V} \mathrm{~s}^{-1}$. 
Scheme 1.

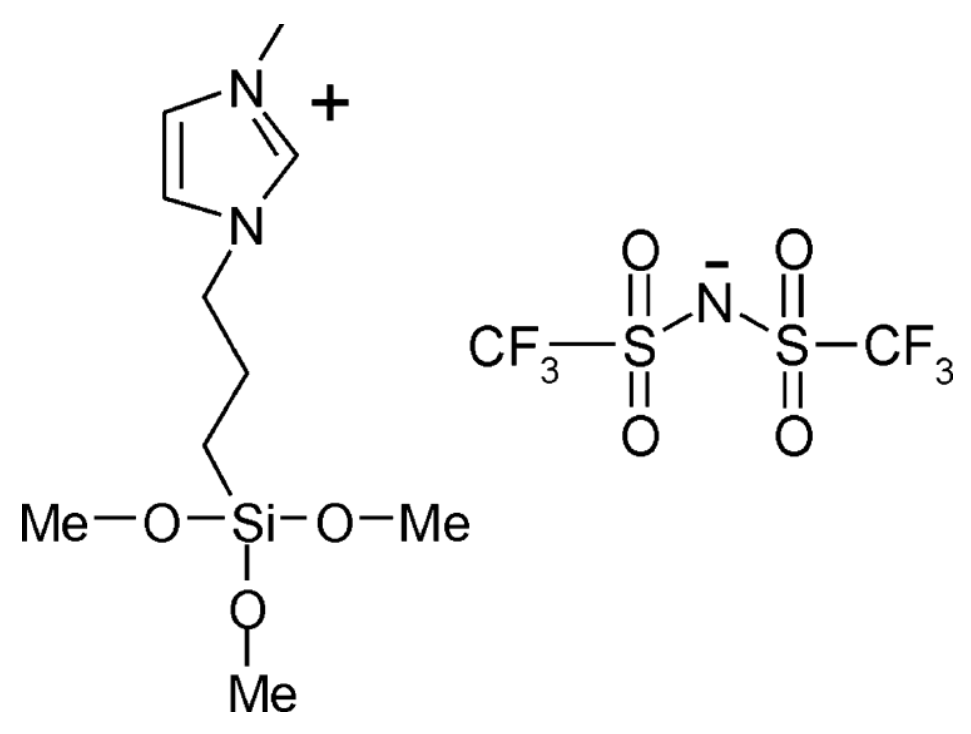


Sheme 2.

(1)

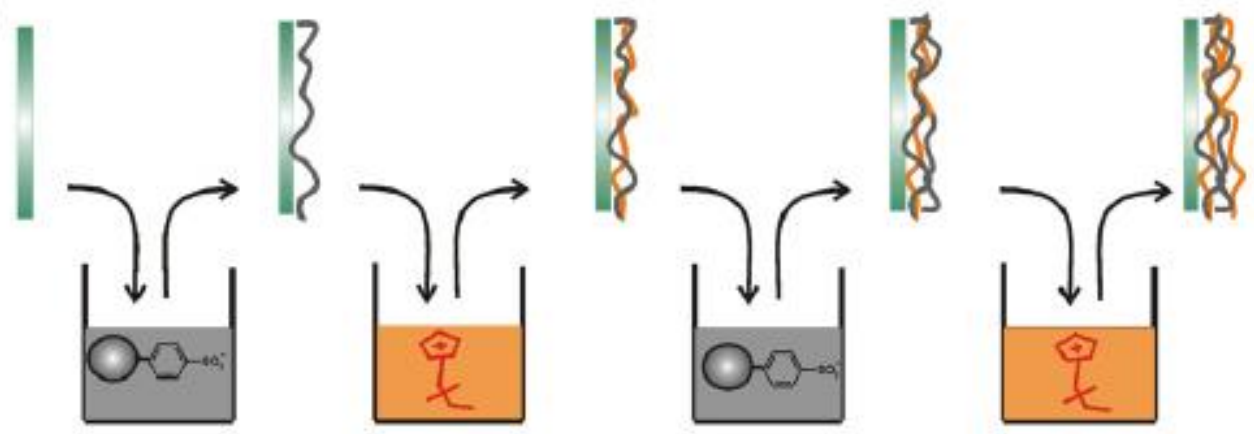

(2)
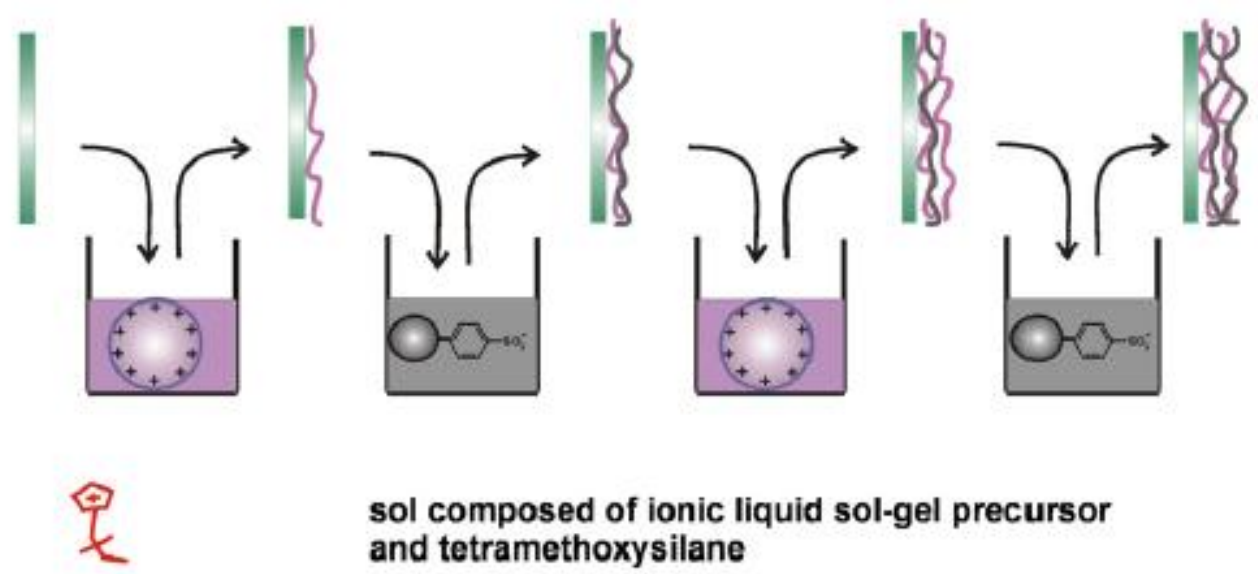

methanolic suspension of silicate submicroparticles with appended imidazolium functional groups

aqueous suspension of carbon nanoparticles modified with phenyl sulphonic groups 
Figure 1.
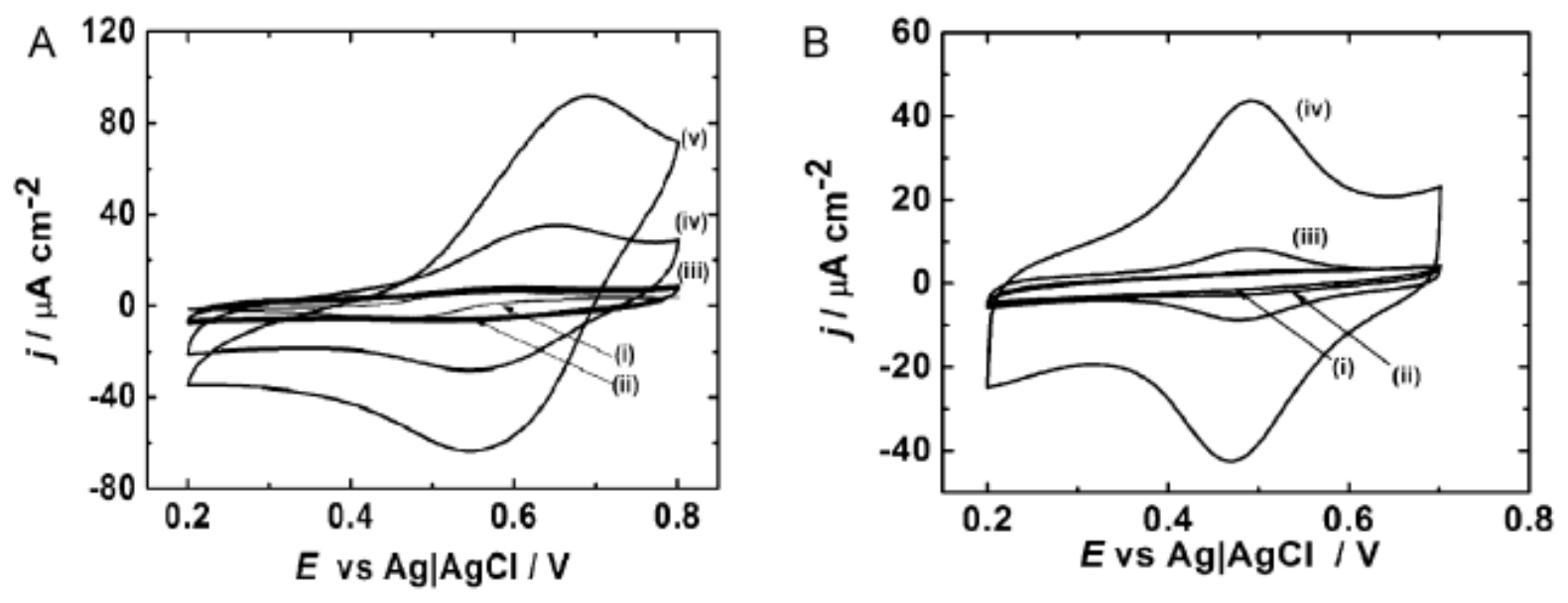
Figure 2.
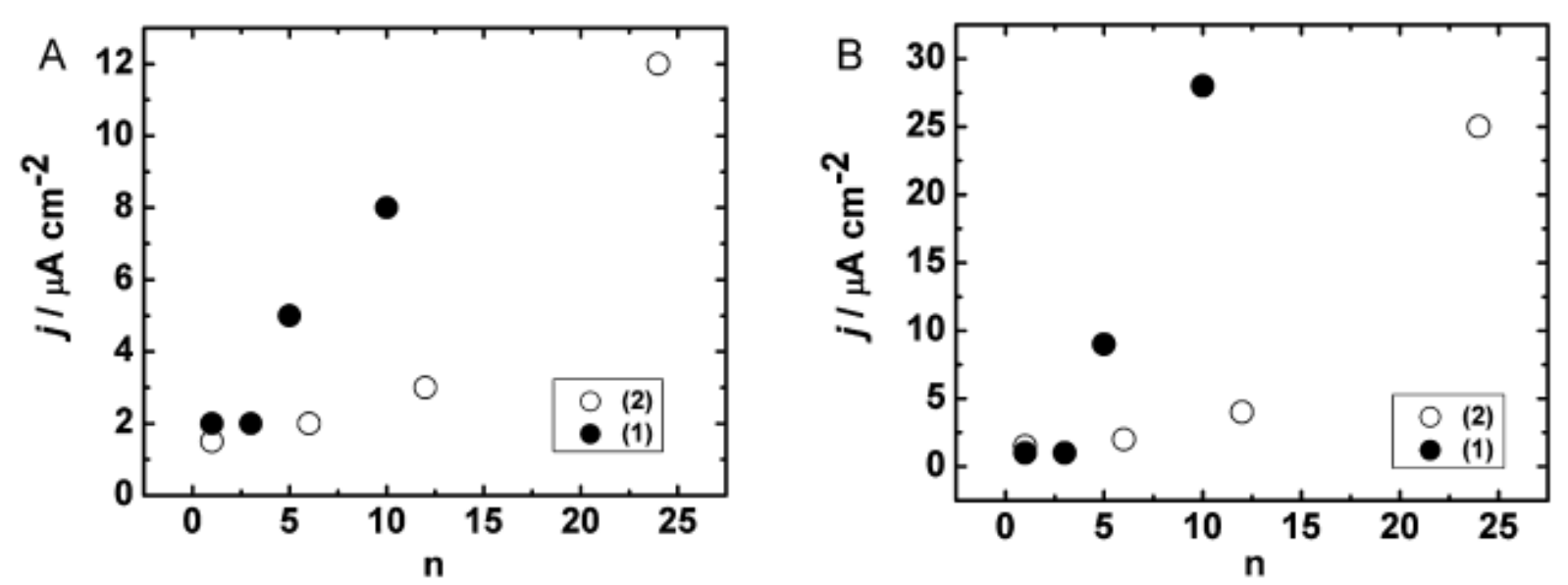
Figure 3.
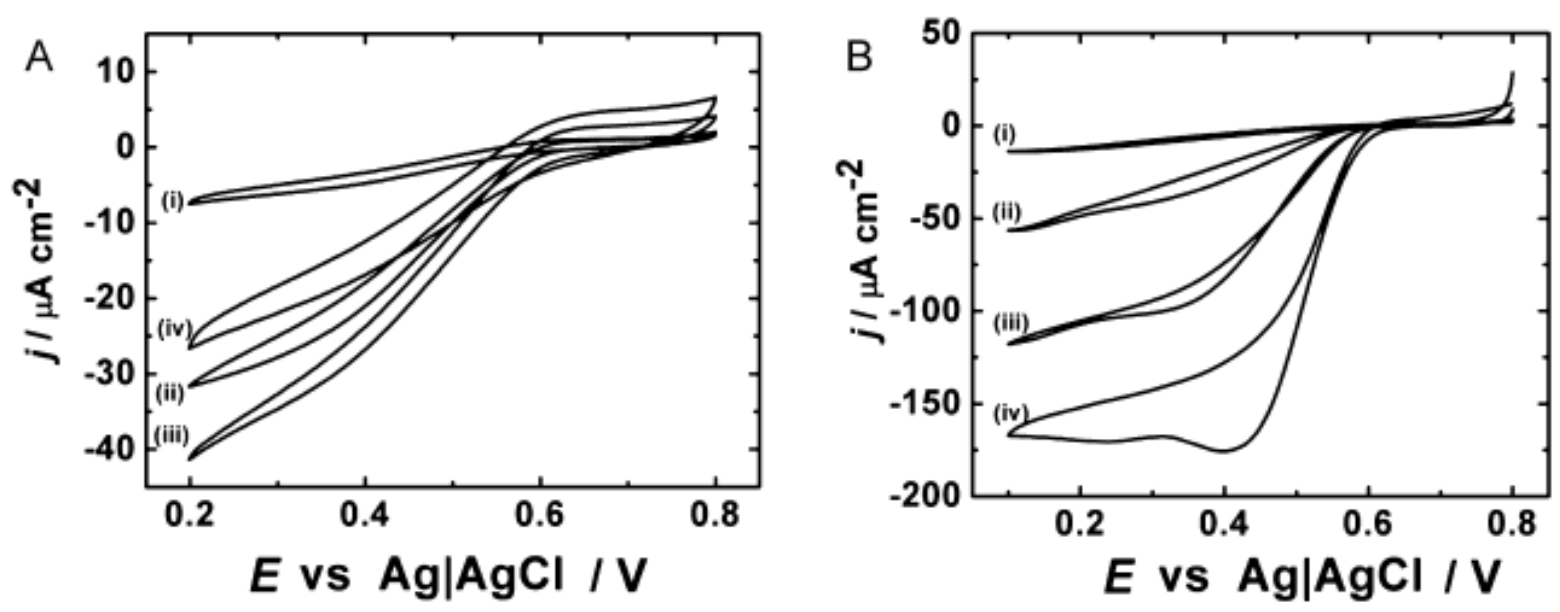
Figure 4.

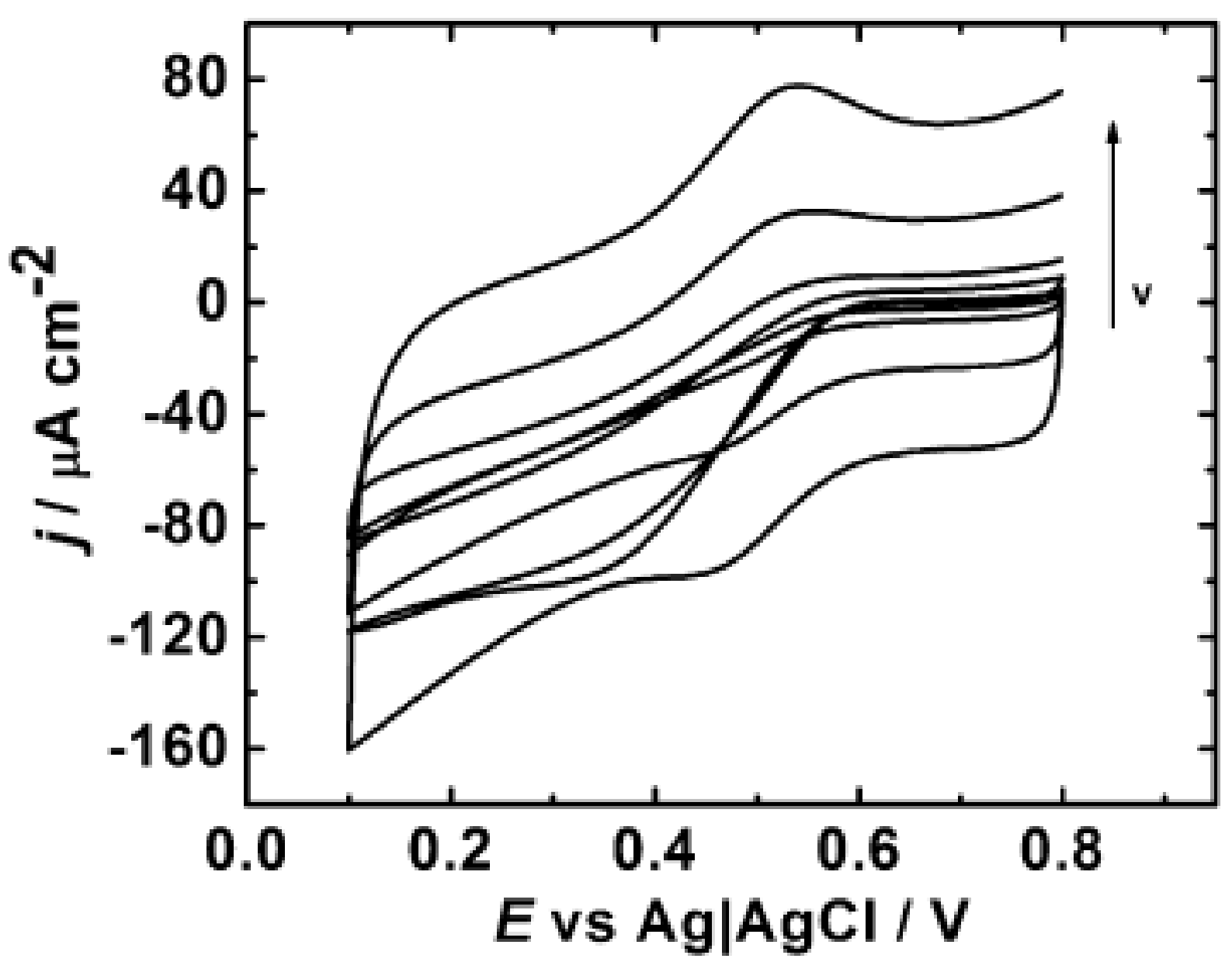


Figure 5.
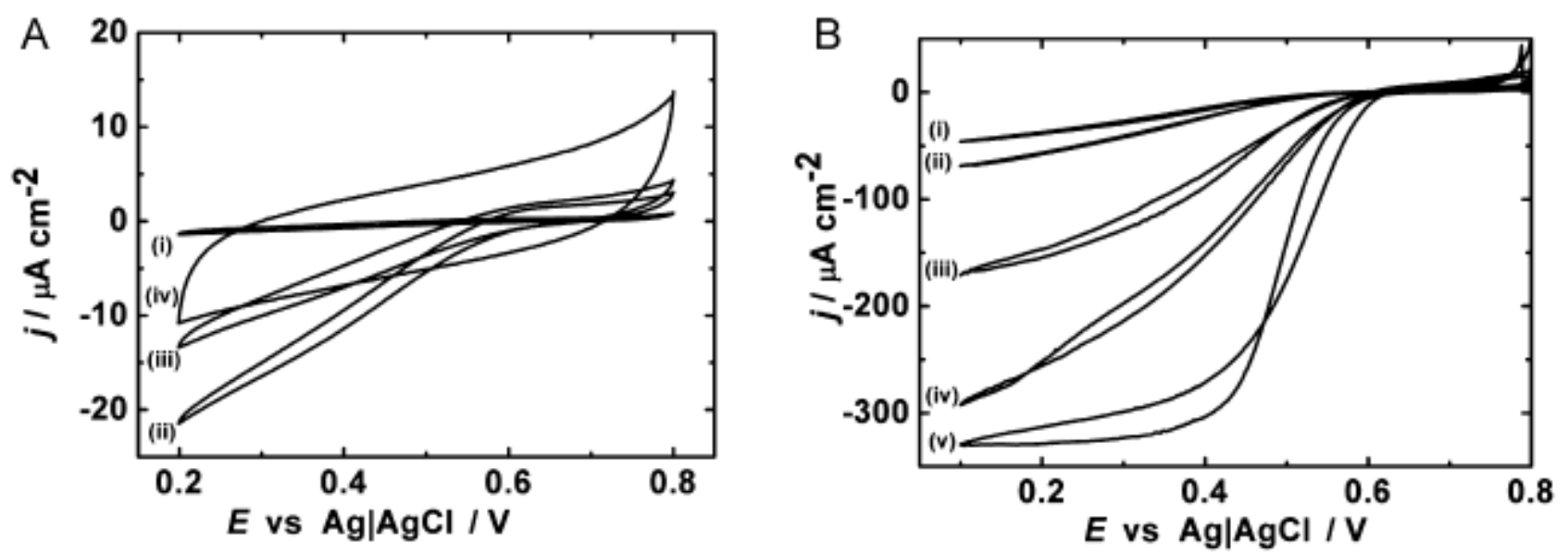
Figure 6.

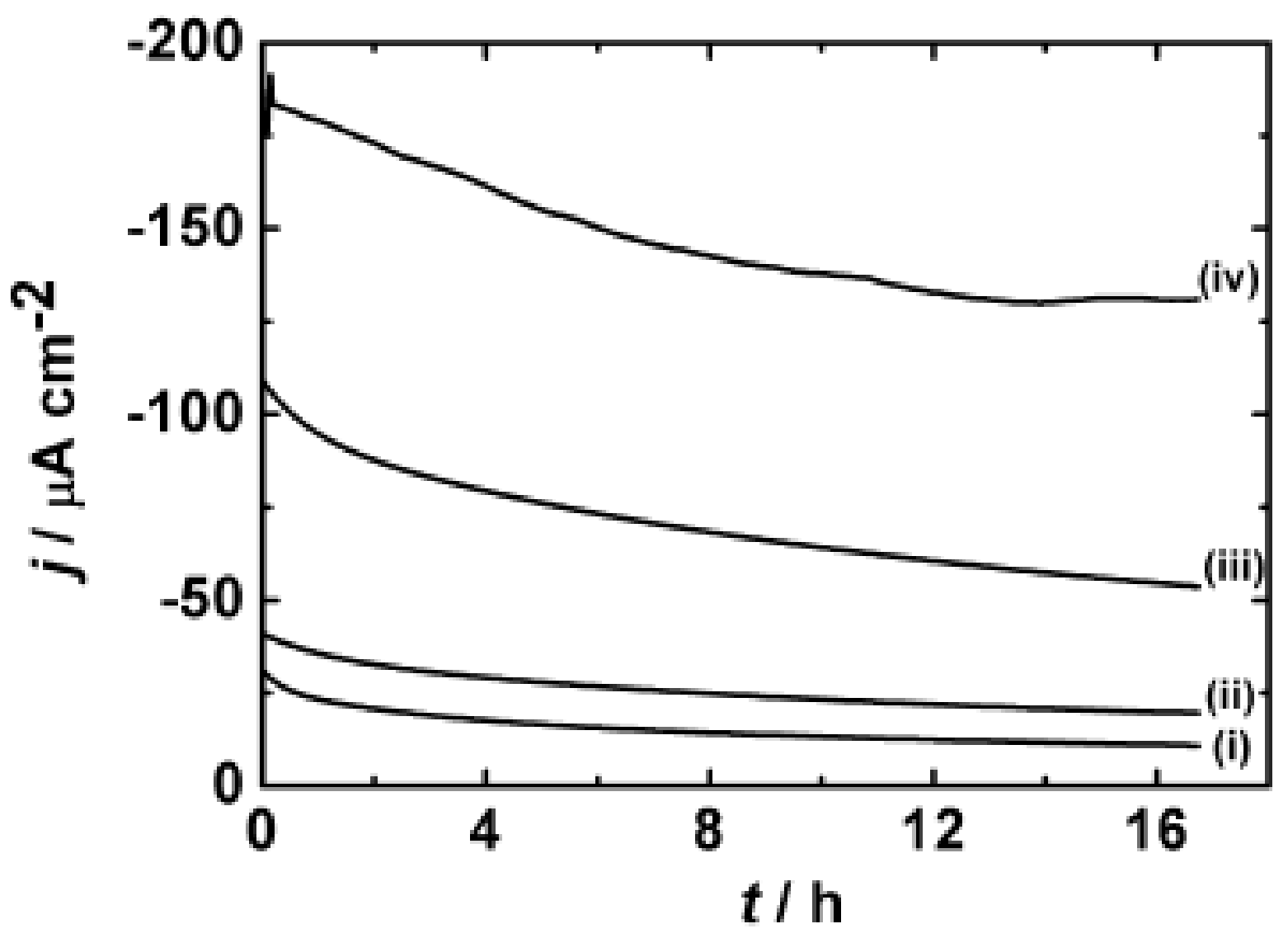


Figure 7.

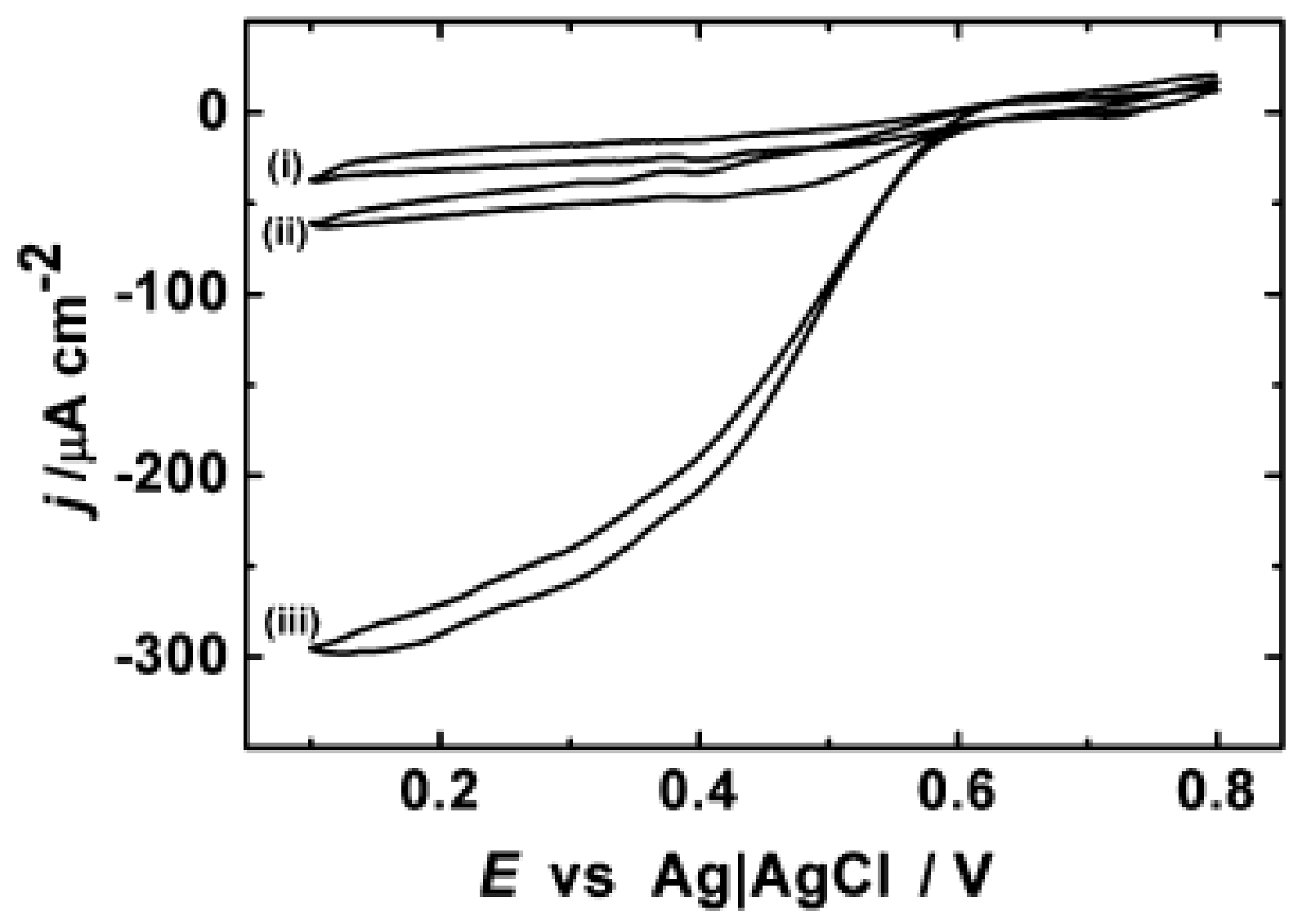

